\title{
Regulação educativa na América Latina: repercussões sobre a identidade dos trabalhadores docentes ${ }^{1}$
}

\author{
Educative Regulation in Latin America: \\ repercussions about the Identity of the teachers work
}

Dalila Andrade Oliveira ${ }^{2}$

\section{Resumo}

O artigo discutirá algumas conseqüências que a nova regulação educativa na América Latina tem tido sobre o trabalho docente, sobretudo, as que se referem às relações de trabalho ou profissionalização e às relativas à identidade docente. Consideramos que a América Latina, a partir dos anos 1990, passou a viver um processo de reformas educacionais que estão inseridas em um contexto de reformas mais amplas ao nível do Estado, e que tais processos resultaram em uma nova regulação educativa. Essa nova regulação traz significativas mudanças à gestão escolar e, por conseguinte, às condições de trabalho nas escolas, o que tem resultado em reestruturação do trabalho docente. As discussões aqui trazidas são resultados de pesquisas realizadas no contexto brasileiro, integradas a investigações em outras realidades nacionais na América Latina.

Palavras-chave: Trabalho Docente; Regulação; Política Educacional; Trabalho e Educação; América Latina

\section{Abstract}

The article argues relative questions to the new educative regulation in Latin America and its impacts on the teaching work, amongst them, two different dimensions : the ones directly related to the relations of work and those that are related to the teaching work identity. We consider that Latin America during the 1990's started to live a process of educational reforms which are related to reforms to the level of the State and that such processes had resulted in a new educative regulation. This new regulation brings significant changes to school management, therefore and to the conditions of work in the schools, which has resulted in reorganization of the teaching work. The discussions presented are the outcomes of researchs in Brazilian context, which were integrated to investigations in other national realities in Latin America.

Keywords: Teaching Work; Regulation; Political Education; Working and Education; Latin America

1 Este artigo foi produzido a partir de estudos e discussões realizadas em estágio de pósdoutoramento, com o apoio da CAPES, no LABRIPROF/CRIFPE/UMONTREAL, sob a supervisão do Prof. Dr. Claude Lessard. É também resultado de pesquisas realizadas no âmbito do GESTRADO, com apoio do CNPq e da FAPEMIG.

2 Socióloga, Doutora em Educação, Professora do Programa de Pós-Graduação em Educação da UFMG (Belo Horizonte/Brasil), Membro da Coordenação da Rede Latino-americana de Estudos Sobre Trabalho Docente (CLACSO) e Pesquisadora do CNPq. dalilaufmg@yahoo.com.br. 
O presente trabalho discutirá questões relativas às conseqüências que a nova regulação das políticas educacionais na América Latina tem tido sobre o trabalho docente. Nosso entendimento é de que essa nova regulação traz significativas mudanças à gestão escolar e às condições de trabalho nas escolas, resultando em reestruturação do trabalho docente. As discussões apresentadas são resultantes de pesquisa documental realizada em três países: Argentina, Brasil e Chile; revisão de literatura sobre o tema; e pesquisa empírica realizada em escolas públicas do estado de Minas Gerais (Brasil).

No contexto educacional latino-americano, com algumas exceções, tais como: Cuba, Argentina, México e Chile, a maioria dos países chega aos anos 1990 sem solucionar a questão da expansão da educação básica para grande parte de sua população. Apesar de a década de 1960 ter sido um marco nas conquistas de alguns direitos sociais neste subcontinente, foram também anos que deram emergência a um longo ciclo de autoritarismo, o que pode explicar, em certa medida, as grandes crises econômicas e políticas que os países latino-americanos se encontraram no início dos anos 1990 e, sobretudo, com população majoritariamente pobre. As reformas educacionais dos anos 1990 tiveram como principal orientação à eqüidade social, o que pode ser interpretado como a formação para o emprego formal e regulamentado permanece como um imperativo para os sistemas escolares, ao mesmo tempo em que estes devem desempenhar papel preponderante na condução de políticas sociais de cunho compensatório que visem à contenção da pobreza. As recentes mudanças nas políticas públicas educacionais no Brasil, especificamente aquelas que tiveram início no primeiro mandato de Fernando Henrique Cardoso e que prosseguem no atual governo do Presidente Luis Inácio Lula da Silva, ilustram bem a referida orientação. O argumento central dessas reformas poderia ser sintetizado na expressão largamente utilizada nos documentos produzidos pelos organismos internacionais pertencentes a ONU como orientação dos governos latino-americanos para a educação: "transformação produtiva com eqüidade social” (CEPAL, 1992).

Essas reformas, no Brasil, trazem uma nova regulação das políticas educacionais. Muitos são os fatores que evidenciam isso, dentre eles, destacam-se a centralidade atribuída à administração escolar nos programas de reforma, situando a escola como núcleo do planejamento e da gestão; o financiamento per capita, com a criação do Fundo de Manutenção e Desenvolvimento do Ensino Fundamental e Valorização do Magistério - 
FUNDEF, por meio da lei n. 9.424/96; a regularidade e a ampliação dos exames nacionais de avaliação, bem como a avaliação institucional e os mecanismos de gestão escolares que pressupõem a participação da comunidade. Esses aspectos, apesar de concernentes à realidade brasileira, encontram similitudes com programas implantados em outros contextos nacionais latino-americanos, tais como Chile (MEDINA; KELLY, 2001) e Argentina (BIRGIN, 2000; FELDFEBER, 2004).

A nova regulação repercute diretamente na composição, estrutura e gestão das redes públicas de ensino. Trazem medidas que altera, nos aspectos físicos e organizacionais, a configuração das redes, forjando adequações segundo os critérios de produtividade, eficácia e excelência presentes nos programas de reforma. A compreensão das interferências que as reformas exerceram sobre as relações de trabalho na escola, sobre os procedimentos normativos que determinam a carreira e a remuneração docente, bem como sobre as implicações sobre a profissão e a identidade docente, precisa ser analisada à luz da especificidade latino-americana.

Partimos da constatação de que a Conferência Mundial sobre Educação para Todos, realizada em Jomtien, em 1990, representou nova orientação para as reformas educacionais dos países mais pobres e populosos do mundo: a educação para a eqüidade social. Para cumprir os compromissos ali estabelecidos, os países em desenvolvimento tiveram que criar estratégias de elevação do nível de atendimento às populações, sem, contudo, aumentar na mesma proporção os investimentos. A redução das desigualdades sociais deveria ser alcançada a partir da expansão da educação, o que permitiria às populações em situação vulnerável encontrar caminhos para a sua sobrevivência (CARNOY, 1992). A educação como meio de distribuição de renda e mobilidade social soma-se à noção de que o acesso à cultura letrada e informatizada se constitui o único meio de ingressar e permanecer no mercado de trabalho, ou sobreviver na chamada "sociedade do terceiro milênio" (DELORS, 1998). Observa-se, então, um duplo enfoque nas reformas educacionais que se implantou nesse período na América Latina: a educação dirigida à formação para o trabalho e a educação orientada para a gestão e disciplina da pobreza (OLIVEIRA, 2000). A fórmula para se expandir os sistemas de ensino desses países, os quais ainda enfrentam processos de reforma do Estado orientada por cortes nos gastos públicos (SALAMA; VALIER, 1997; CALCAGNO, 2001), será elaborada por meio de estratégias de gestão e financiamento, que vão da focalização das políticas públicas educacionais ao apelo ao voluntarismo. 
Assim, essas reformas são marcadas pela padronização de processos administrativos e pedagógicos, os quais possibilitam baixar custos e redefinir gastos, sem, contudo, abrir mão do controle central das políticas. O modelo de gestão escolar adotado combina formas de planejamento e de controle central para formulação de políticas com a descentralização administrativa na execução destas. Tais estratégias possibilitam arranjos locais, como a complementação orçamentária com recursos da própria comunidade e a busca de parcerias junto ao setor privado. A eqüidade se fará presente nas políticas de financiamento a partir da definição de custos mínimos assegurados a todos. A flexibilidade presente nesse modelo é colocada em prática mediante a descentralização administrativa, que representa a transferência de obrigações dos órgãos centrais às escolas e à municipalização do ensino fundamental. A descentralização financeira, que permite à escola maior flexibilidade na gestão e captação de recursos externos, e a descentralização pedagógica - elaboração coletiva do Projeto Pedagógico pelo estabelecimento de ensino - são dimensões insdispensáveis desse modelo.

A expansão da educação básica realizada dessa forma tem sobrecarregado, em grande medida, os trabalhadores docentes. Essas reformas têm resultado em reestruturação do trabalho pedagógico proveniente da combinação de diferentes fatores que se fazem presentes na gestão e organização do trabalho escolar, tendo como corolário, maior responsabilização dos professores e maior envolvimento da comunidade.

\section{Os tRabalhadores docentes \\ NAS REFORMAS EDUCACIONAIS LATINO-AMERICANAS}

Os professores são, em geral, considerados os principais responsáveis pelo desempenho dos alunos, da escola e do sistema, no contexto atual de reformas educacionais e de uma nova regulação educativa. Diante das variadas funções que a escola pública assume, os professores encontram-se freqüentemente diante da necessidade de responder às exigências que estão para além de sua formação. Importante observar que, em contexto de pobreza, a escola é, freqüentemente, a única agência pública local. Em numerosos municípios brasileiros em que inexistem postos de saúde, parques de lazer, centros de cultura, entre outros espaços públicos, a escola acaba sendo o único espaço para que os problemas de saúde sejam minimamente tratados (ou apenas conhecidos) e possibilidade de acesso cultural dos alunos e de toda comunidade. Nessas 
escolas os professores se sentem obrigados a desempenhar funções que estão para além de suas capacidades técnicas e humanas. Nesse sentido, não se encontram no ambiente escolar da maioria das escolas públicas brasileiras e, em certa medida, latino-americanas profissionais capacitados a responder a essas exigências: os professores são constrangidos a buscar respostas para essas demandas.

No caso brasileiro, soma-se a esses fatores a consagração, na Constituição Federal de 1988, do princípio de gestão democrática do ensino público, artigo 206, inciso VI. Esse dispositivo, apesar de representar uma conquista dos movimentos sociais, traz novas exigências para a escola. Os trabalhadores devem participar da gestão da escola, da escolha direta para diretores e coordenadores escolares, além de representação junto aos conselhos escolares, dos quais eles devem ser eleitores e postulantes. Além disso, a gestão democrática pressupõe o trabalho coletivo de elaboração do planejamento escolar e dos programas e currículos. É também uma conquista desse momento a ampliação de 180 dias letivos para 200, ou 800 horas. Assim, podemos considerar que houve uma dilatação, no plano legal, da compreensão do que seja o pleno exercício das atividades docentes. Todavia, o trabalho docente deve contemplar as atividades em sala de aula, as reuniões pedagógicas, a participação na gestão da escola, o planejamento pedagógico, entre outras atividades. Tais exigências são coerentes à nova regulação educativa que, em certa medida, com as reformas educacionais mais recentes, toma lugar em muitos países no mundo (DUTERCQ; LANG, 2002; CATTONAR; MAROY, 2001; BARROSO, 2004; LESSARD; TARDIF, 2004).

Este quadro de nova regulação educativa no contexto latinoamericano resulta em significativa intensificação do trabalho; precarização das relações de emprego, mudanças consideráveis nas relações de trabalho que repercutem sobre a identidade e condição docente (FANFANI, 2005; OLIVEIRA, 2005). No presente trabalho, tentaremos discutir como tais repercussões vêm sendo percebidas a partir de pesquisas realizadas no contexto escolar público latino-americano.

\section{A Intensificação do tRabalHO}

Tendo sido tratada em alguns trabalhos que tiveram como referência o contexto europeu ou norte-americano (APPLE, 1995; HARGREAVES, 1998; CONTRERAS, 2002), a intensificação do trabalho, assume características específicas na realidade latino-americana atual. Podemos 
observar a intensificação do trabalho docente resultante de ampliação da jornada de trabalho e do aumento considerável de responsabilidades que os docentes tiveram com as reformas mais recentes.

Os trabalhadores docentes, em muitos países latino-americanos, estão sujeitos à ampliação da jornada individual de trabalho em razão de assumirem mais de um emprego (OLIVEIRA, 2003; FANFANI, 2005). Apesar de ser a minoria que assume outro emprego que não a docência (FANFANI, 2005; CNTE, 2003), os professores que trabalham em escolas públicas costumam assumir mais de uma jornada de trabalho como docente em diferentes estabelecimentos. Um mesmo professor leciona em dois ou até três estabelecimentos distintos, em geral, por necessidade de complementação de renda, tendo em vista que os salários do magistério, na América Latina, são baixos, comparativamente a outras funções exigentes de formação profissional similar. Nesses casos, o professor não se identifica com uma escola em particular. Por assumir número considerável de aulas, esses professores acabam por não conhecerem bem a maioria de seus alunos, e não encontram tempo para atividades que julgam importantes para o bom desempenho profissional, como: preparar aulas, estudar, atualizar-se (NORONHA, 2001). Segundo pesquisa realizada pela CNTE (2003), os professores gastam, em média, 22 horas mensais em casa com trabalhos de preparação de aulas.

Uma forma de intensificação do trabalho docente é aquela decorrente também da extensão da jornada de trabalho, porém dentro do próprio estabelecimento escolar em que atua. Trata-se de um aumento das horas e carga de trabalho sem qualquer remuneração adicional. Observamos tal fato principalmente entre os diretores de escolas. Em pesquisa realizada na Rede Municipal de Ensino de Belo Horizonte, Minas Gerais, 92\% dos entrevistados informaram trabalhar mais de oito horas diárias (jornada remunerada), e 93\% afirmavam "levar trabalho para casa". Esta rede era composta, à época, por 179 escolas, a pesquisa contou com 127 entrevistados, de um conjunto de 358 diretores e vice-diretores (OLIVEIRA; GONÇALVES, 2002).

Outra dimensão importante da intensificação do trabalho docente, e talvez a mais preocupante, é a que ocorre na jornada de trabalho remunerada, caracterizando-se, portanto, em estratégias mais sutis e menos visíveis de exploração. Os trabalhadores docentes incorporam ao seu trabalho novas funções e responsabilidades, premidos pela necessidade de responder às exigências dos órgãos do sistema, bem como da 
comunidade. Essa terceira dimensão justifica-se pela incorporação de certa flexibilidade nas políticas educacionais que promovem maior desregulamentação para prover a escola de maior liberdade administrativa, conforme já comentado. Tudo isso em um contexto em que, por força da própria legislação e dos programas de reforma, os trabalhadores docentes se sentem forçados a dominarem novas práticas, novos saberes e o domínio de certas competências no exercício de suas funções. A pedagogia de projetos, a transversalidade dos currículos, as avaliações formativas: são muitas as novas exigências que esses profissionais são forçados a responder. Sendo apresentadas como novidade ou inovação, tais exigências são tomadas pelos docentes, muitas vezes, como naturais e indispensáveis.

\section{Precarização do trabalho docente}

Uma das principais mazelas da flexibilidade contida nos processos de reformas é a precarização do trabalho. As mudanças ocorridas nas relações de trabalho e de emprego têm sido caracterizadas, na atualidade, pela ameaça de um fenômeno considerado por alguns autores como precarização das relações de trabalho. Esse movimento, contudo, não se circunscreve às relações de trabalho caracterizadas como intrínsecas ao processo de trabalho, mas compreende, principalmente, as relações de emprego, apresentando tentativa de flexibilização, e até mesmo desregulamentação da legislação trabalhista.

Esse processo está na base do que Castel (1999), discutindo as transformações da questão social, considera como um questionamento da função integradora do trabalho hoje na sociedade. Esse autor demonstra que o sistema de proteções e garantias sociais vinculadas ao trabalho vai sendo desmontado para se determinar o que caracteriza como "um processo de precarização que atinge as situações do trabalho, no sentido da sua re-mercantilização e de soluções na ordem do mercado, como efeito particular da globalização" (p. 166-167).

O que se considera como processo de precarização do trabalho no contexto latino-americano decorre do modelo de crescimento econômico adotado que não prevê a ampliação do número de empregos, o que tem contribuído para o acirramento das desigualdades sociais neste começo de século (POCHMANN, 1999). Apresenta-se como questão preocupante nesse contexto o aparecimento de novas formas de ocupação que têm provocado maior segmentação do mercado de trabalho. A flexibilidade 
dos contratos de trabalho e das legislações social e trabalhista, a queda nas taxas de sindicalização e o reduzido número de greves revelam maior grau de autonomia das empresas. No caso do magistério público, essas relações aparecem sob a forma de contratos temporários de trabalho que não asseguram os mesmos direitos e garantias dos trabalhadores efetivos (OLIVEIRA; MELO, 2004).

Podemos considerar que, como o trabalho em geral, o trabalho docente tem sofrido relativa precarização nos aspectos concernentes às relações de emprego. $\mathrm{O}$ aumento dos contratos temporários nas redes públicas de ensino, chegando, em alguns casos, a número correspondente ao de trabalhadores efetivos; o arrocho salarial; ausência de piso salarial; inadequação ou mesmo ausência, em alguns casos, de planos de cargos e salários; a perda de garantias trabalhistas e previdenciárias oriunda dos processos de reforma do Estado têm tornado cada vez mais agudo o quadro de instabilidade e precariedade do emprego no magistério público. Cabe ainda ressaltar que, em levantamento realizado recentemente, foi possível constatar que as questões salariais e de caráter profissional, aquelas atinentes à defesa dos direitos trabalhistas, ainda são as mais contundentes nas lutas e manifestações dos trabalhadores docentes no contexto latinoamericano (OLIVEIRA; MELO, 2004; GENTILI; SUARES, 2004). Isso se explica pela precarização das condições de trabalho e remuneração que esses profissionais se submeteram nos últimos anos. O fato é que o trabalho docente tem se reestruturado, dando lugar a uma nova organização escolar. Contudo, essas transformações não vieram acompanhadas das adequações necessárias, por exemplo, os professores continuam sendo contratados e remunerados por horas/aula, quando na atualidade se exige deles que participem de atividades "extraclasse".

\section{Repercussões sobre a profissão e identidade docente}

A discussão sobre a identidade docente é pautada no Brasil a partir dos anos 1980, tanto do ponto de vista político quanto acadêmico. É no final da ditadura militar (1964+1985), especificamente nos últimos anos do regime, que o movimento sindical ganha proeminência na cena política brasileira (SADER, 1981). Dentre as categorias em manifestação, o magistério público teve papel preponderante na condução das greves que emergiram naquele momento. Estava na base das discussões dos trabalhadores docentes, naquele momento, a questão da identidade e do profissionalismo. Foram muitos estudos que nesse período levantaram 
questionamentos e reflexões sobre a relação tênue entre o espaço doméstico e a escola como local de trabalho, a negação da identificação do magistério com a tarefa de guia espiritual e moral, as dificuldades de reconhecimento social e profissional desses trabalhadores (ARROYO, 1985).

Esse período assistiu a uma luta intensa pelo reconhecimento do direito de organização sindical desses trabalhadores no contexto do novo sindicalismo brasileiro, que foi bastante influenciado pelo princípio de organização classista presente na criação da Central Única dos Trabalhadores (CUT), que dá origem à defesa da categoria dos trabalhadores de educação - incluindo, de professores e especialistas a funcionários administrativos e de serviços gerais. A busca de construção de uma identidade única que congregasse todos os trabalhadores da educação alenta as lutas sindicais das duas décadas seguintes e está refletida no nome e estatutos das instituições sindicais criadas nessa época, a União dos Trabalhadores do Ensino em Minas Gerais é um exemplo.

As reformas educacionais dos anos 1990 chegam a um período de relativa estabilização da luta política sindical, marcada por fraca mobilização de base e burocratização das direções sindicais. Observa-se um distanciamento entre o sindicato e o cotidiano escolar, no sentido de que ele se apresenta pouco atento às mudanças mais recentes que atingem a escola, assim como às repercussões dessas sobre a subjetividade dos professores (FANFANI, 2005; OLIVEIRA; MELO, 2004). Na atualidade, trinta anos passados, podemos observar que os sindicatos não tiveram êxito em forjar a identidade de trabalhadores de educação, perseguida nas lutas sindicais classistas dos tempos de ditadura. É nítida a separação entre professores e funcionários dentro das escolas. Tal separação parece ter sido ainda mais reforçada à medida que muitas redes públicas passaram a terceirizar os serviços de vigilância, limpeza e, em alguns casos, até mesmo funções administrativas. A separação entre funcionários e professores fica evidenciada na protagonização de conflitos docentes. Em pesquisa recente, observamos que a grande maioria dos conflitos manifestos teve como protagonistas os professores (OLIVEIRA; MELO, 2004).

Tal separação é explicada, sobretudo, pelo argumento da identidade, definida pelo critério de interesse econômico e de status profissional. Além de possuírem maior titulação e ter maior remuneração, os professores são os responsáveis pela atividade fim da escola. Dessa maneira, encarnam, 
pelo menos formalmente, a responsabilidade por fazer cumprir a missão da escola. Por parte dos funcionários é possível encontrar um comportamento que expresse menos compromisso com as atividades fins, não estabelecendo vínculos mais estreitos com a tarefa educativa. Isso, em parte, se explica pelo caráter instável do contrato de trabalho, ou mesmo pela rotatividade dos trabalhadores terceirizados, que ainda que mantenham seus contratos com a empresa contratante, podem, muitas vezes, mudarem seu local de trabalho. Isso impede que esses empregados tenham vínculos mais duradouros ou estáveis com a escola, o que pode determinar o nível de comprometimento deles com as finalidades do estabelecimento de ensino em que atuam. Mas essa não é uma relação que pode ser explicada pelo desinteresse ou falta de motivação dos empregados terceirizados, pois, mesmo em escolas que ainda conservam razoável número de funcionários de apoio efetivos, é possível observar essa divisão entre os professores, ou pessoal responsável pelo que definimos como ensino ou docência, e os demais trabalhadores da escola.

Outra característica importante da organização escolar reveladora dessa identidade cindida ou jamais constituída (ficando apenas no ideal dos militantes docentes de décadas passadas) é a divisão entre professores e especialistas. Nesse caso, a divisão se revela de outra maneira: os especialistas que ocuparam posição de destaque na hierarquia escolar, apresentando-se como superiores ao corpo de docentes, tiveram, no contexto dessas lutas sindicais, seus papéis duramente criticados. As críticas à hierarquização, centralização da administração escolar e ao modelo burocrático e centrado nas especializações levaram a consolidação de outras referências de gestão educacional, inscrita na Constituição Federal de 1988, art. 206, inciso VI, conforme já mencionado. O princípio constitucional da gestão democrática do ensino público acabou por ser regulamentado em muitas redes pela escolha direta do diretor escolar pela comunidade, o que contribuiu para que a função do administrador escolar fosse se extinguindo em muitas redes de ensino. Além dos diretores, os coordenadores de escolas surgem nesse contexto ocupando, em algumas redes, o papel que outrora ocupavam os especialistas. Assim, algumas redes passaram a eleger ou contratar coordenadores pedagógicos em substituição às funções de supervisão e orientação escolares. Essas mudanças repercutiram na formação do pedagogo.

Observa-se, a partir desse momento, tendência crescente de os professores passarem a ocupar, por meio de escolha livre e direta de seus 
pares e da comunidade, as funções antes designadas aos especialistas. Simultaneamente, os funcionários de apoio administrativo e serviços gerais diminuem por falta de reposição do quadro funcional, que por motivos de aposentadoria, morte ou dispensa não são substituídos. Isso, ao contrário do que propugnavam os sindicatos nos finais dos anos 1970 e início dos 1980, aprofunda a distância entre docentes e funcionários, concentrando na função docente maior responsabilidade e acúmulo de trabalho.

LeVasseur e Tardif (2004, 2005), ao discutir as relações de trabalho entre técnicos e docentes na divisão do trabalho nas escolas de Québec (Canadá), demonstram que tal divisão considera elementos técnicos e igualmente sociais, o que determinam em boa parte as relações profissionais entre os agentes escolares e, ao mesmo tempo, contrariam as possibilidades de uma gestão puramente racional. As difíceis relações observadas por esses autores num contexto em que professores e pessoal técnico trabalham conjuntamente, sem necessariamente expressar relação de colaboração, é contrastante com a realidade escolar latino-americana, na qual os professores tendem a assumir cada vez mais a escola em sua totalidade. Esses autores observaram em suas pesquisas que as atuais exigências de um trabalho mais colaborativo e em equipe são fontes de tensões e de conflitos entre os funcionários e professores na realidade quebequense, provocando confusão de papéis dentro da escola. No caso brasileiro, o imperativo da gestão democrática tem demandado dos professores maior compromisso com a escola, ao mesmo tempo em que se exige deles a capacidade de colaborar, de trabalhar em equipe, de discutir coletivamente. Contudo, observamos também tensões entre funcionários e professores na escola pública brasileira similares às discutidas pelos autores citados. Ainda que o conteúdo dessas tensões possa ser de natureza distinta, revelam muita similaridade quanto à forma. A superioridade dos professores sobre os funcionários de apoio, resultando, na maioria das vezes, em subordinação dos segundos aos primeiros, se justifica pela competência técnica e profissional, por exemplo. Ainda que formalmente todos estejam a serviço de uma mesma finalidade, para com os professores parece haver uma relação direta de responsabilização pelo sucesso ou fracasso dos fins perseguidos.

Com relação aos especialistas da realidade brasileira, a separação ocorre de outra maneira. A crítica à administração racional forjou uma nova concepção de gestão escolar fundada na discussão coletiva e na participação dos sujeitos. Essas críticas acabaram por desautorizar, em 
grande medida, os especialistas em relação aos seus status e domínios profissionais. Durante os anos 1980, as críticas à administração escolar de orientação empresarial engendraram um novo paradigma de gestão escolar no Brasil, que teve como resultado maior autonomia e participação democrática (OLIVEIRA, 2004). Tais constatações nos levam a indagar se houve, de fato, em algum momento na história da profissão docente no Brasil, uma tendência de todo o conjunto de trabalhadores da escola a se identificar como trabalhadores de educação na perspectiva autônoma e horizontal apontada pelos movimentos em defesa da democratização da educação. E em que medida essa identidade não foi uma criação artificial das lideranças políticas que tentaram transpor para dentro da escola valores de solidariedade e igualdade que jamais encontraram correspondência na prática desses trabalhadores. Contudo, ao mesmo tempo, essa busca de identidade única estava vinculada a uma mudança na concepção de educação a qual não poderia ser tomada como uma atividade transmissiva, restrita à sala de aula, mas como uma relação que propiciasse a autonomia e emancipação dos sujeitos.

As reformas educacionais mais recentes trazem uma forte retórica que valoriza aspectos da luta por uma educação mais democrática que se faz com e para sujeitos autônomos e emancipados. As noções de coletividade, autonomia e participação são fortemente evocadas nos documentos das reformas educativas atuais (PREAL, 2004; CEPAL, 1990), porém compreendidas em uma abordagem que privilegia o elemento da flexibilidade. É possível observar que essa maior flexibilidade, tanto nas estruturas curriculares quanto nos processos de avaliação, corrobora com a idéia de que estamos diante de novos padrões de organização, inclusive, do trabalho escolar, que podem estar forjando um novo perfil de trabalhadores docentes e uma nova identidade. Ocorre, porém, que esses novos modelos de organização escolar expressam muito mais um discurso sobre a prática do que a própria realidade. Nesse sentido, as observações sobre o trabalho em si, no momento da sua realização, nos parecem vitais.

Cattonar e Maroy (2001) ao discutir a retórica da mudança no métier profissional, a partir de elementos da realidade belga francofônica, apontam para a mesma direção as exigências presentes nos documentos das reformas mais recentes. Demonstram que a retórica sobre a transformação do métier docente não visa só a mudança técnica nas formas de ensinar e algumas competências, mas uma mudança mais profunda na identidade profissional dos docentes. 
É na experiência concreta que a especificidade latino-americana se revela. A retórica reformista para os países latino-americanos não difere muito dos discursos e propostas de reformas dos países da América do Norte e da Europa. São as mesmas proposições que encontramos nos programas de reforma para contextos nacionais muito distintos, ressalvando que para os países latino-americanos algumas medidas compensatórias são explicitamente sublinhadas.

Medina e Kelly (2001) consideram que as exigências atualmente formuladas de maior profissionalismo dos docentes no quadro de reformas dos sistemas escolares nos países da América Latina visam melhor qualidade da educação baseada essencialmente no desenvolvimento da autonomia do professor. O que significa passar de um modelo de funcionalismo ou técnico da gestão pedagógica para um modelo de exercício da autonomia, em que o professor deve possuir as condições de propor ações e resolver os problemas de acordo com seu contexto. Esses autores identificam dois grupos de demandas internas e externas ao sistema escolar nesse contexto. Um primeiro no qual se pode assinalar aquelas derivadas da massificação da educação, dos fenômenos de descentralização e privatização que tem gerado um aumento da heterogeneidade. Nesse caso, torna-se necessário adaptar as metodologias de ensino às realidades locais e eventualmente gerar respostas imediatas. E um segundo grupo que se refere àquelas concernentes às demandas socioculturais externas aos sistemas escolares em que se exige o domínio de certas competências e códigos de linguagem, vitais aos processos de formação de cidadania coerente às demandas do mundo complexo e dinâmico de hoje. Identificam, assim, que as demandas trazidas pelas mudanças curriculares e pedagógicas mais recentes expressam uma forma de exercício profissional caracterizado por duas dimensões: um modo de fazer fundado sobre a reflexão, a autonomia, a flexibilidade e a capacidade de gerar - individual e coletivamente - respostas adequadas às situações particulares; e uma relação com o conhecimento que permite o desenvolvimento de aprendizagens significativas.

O quadro descrito pelos autores previamente citados, a partir da realidade chilena, pode ser confirmado no Relatório da Comissão Européia para Educação (DELORS, 1998). Apesar de os autores chilenos considerarem que no primeiro grupo de demandas inexiste, em geral, a capacidade de reflexão que se supõe dos professores, parecem considerar que, de fato, a tomada de decisão desceu de um nível central à escola. 
Nosso entendimento é de que questões de grande importância, que podem, de fato, mudar a estrutura dos sistemas escolares, não são descentralizadas. Estamos em face de um processo de desregulamentação do trabalho e da educação para setores que economicamente não têm condições de interferir nos rumos do desenvolvimento e nem mesmo de se integrarem de forma economicamente ativa nesta sociedade. Para esses autores, a educação deve ser ministrada a um custo mínimo, a partir de arranjos locais. Estamos diante da tensão entre local e global, tratada nesses processos de reforma como estratégias de governo local e administração descentralizada (BAUMAN, 1999; DUTERCQ; LANG, 2002).

É inegável, entretanto, que essas reformas trazem novidades do ponto de vista organizacional, decorrentes de processos de luta e manifestação crítica às formas tradicionais de administração escolar e metodologias de ensino. A legitimação de práticas coletivas de trabalho e de reconhecimento de maiores direitos dos alunos como sujeitos sóciohistóricos são ganhos incontestáveis deste momento, apesar de não estarem garantidas as condições objetivas necessárias à plena realização desse exercício. Referimo-nos à remuneração de horas de trabalho, aos espaços, aos recursos didáticos, entre outros fatores que não podem ser menosprezados. Apesar de sabermos que a ausência dessas garantias não é prerrogativa dos países latino-americanos, insistimos que em contexto de maior pobreza, ganham proeminência.

Poderíamos considerar que grande parte das escolas públicas brasileiras (ou quem sabe latino-americanas?) poderia ser descrita utilizando-se a tipologia de escolas dificeis de Kerroubi e Zanten (2002), criadas a partir da realidade francesa: escolas que se desenvolvem em um contexto de pobreza, de precariedade material, cujos alunos apresentam significativo déficit cultural. Para o contexto latino-americano essa não é a exceção, mas a regra. Soma-se a isso o desencantamento desses jovens diante da baixa expectativa de futuro, a incerteza quanto às suas possibilidades de ingresso no mercado de trabalho. Nesse contexto, os alunos estão distantes do que seria o modelo de aluno ideal, trazem para a escola problemas de naturezas diversas, contribuindo para um ambiente tenso em que a violência ameaça a todos.

Birgin (2000) ao abordar a nova regulação sobre os docentes no contexto argentino, observa que com a massificação do ensino não só alunos com déficit cultural chegam às escolas, como também professores que apresentam grande defasagem cultural, por se encontrarem em 
condições econômicas bastante desfavoráveis. No caso argentino, tais condições foram ainda mais agravadas com a crise de 2001. É justamente sobre esse corpo docente pouco preparado para o enfrentamento diário da escola que as maiores exigências e responsabilidades são direcionadas.

\section{Considerações finais}

A nova regulação educativa interfere na organização de todo o sistema escolar, passando por todas as mediações até à escola. Um redesenho da organização e gestão desses sistemas está sendo esboçado, e há muita contradição nesse processo. A força com que os sistemas escolares continuam a ter nos processos de regulação social é indiscutível, quer na formação da força de trabalho, quer como disciplinadores da população, papel que ganha relevância no que se refere aos pobres, em face das transformações sociais atuais. Sendo assim, a função da escola regular não se restringe à qualificação para o trabalho formal, mas deve contemplar a divisão do trabalho com a complexidade recente trazida pelo crescimento dos setores informais. Por essas razões, a regulação das políticas educacionais, na atualidade, contém essa ambivalência. Os programas de reforma que se propõem a organizar a educação básica, de caráter geral, com o papel de formar a força de trabalho adequada às exigências últimas do capitalismo também objetivam disciplinar a pobreza.

Essa nova regulação educativa apresenta algumas especificidades no contexto latino-americano. A centralidade atribuída aos docentes nos processos de mudança acarreta exigências significativas para esses trabalhadores, o que repercute sobre suas condições de trabalho e sua identidade. A defasagem entre o que é propagado nos discursos oficiais e nos documentos que propõem essas reformas e a prática concreta dos trabalhadores extrapolam, em muito, as já conhecidas análises sobre a distância entre o trabalho prescrito e real. Não podemos considerá-las somente do ponto de vista objetivo, em que pese o fato de que as condições materiais de trabalho representam um problema considerável, mesmo na realidade européia e da América do Norte, e que nos países latinoamericanos têm sido um grande problema. As exigências apresentadas aos professores, no contexto de nova regulação educativa, pressupõem maior responsabilização dos mesmos, demandando maior autonomia, capacidade de resolver localmente os problemas encontrados, refletir sobre a sua realidade e trabalhar de forma coletiva e cooperativa, estando elas além de suas condições objetivas e subjetivas. 
Dessa maneira, podemos perceber que o movimento de reformas que toma corpo nos países da América Latina a partir dos anos 1990, demarcando uma nova regulação educacional, traz conseqüências significativas para a organização e gestão escolares, resultando em uma reestruturação do trabalho docente, podendo alterar, inclusive, sua natureza e definição. $O$ trabalho docente não é definido apenas como atividade em sala de aula, devendo compreender a gestão da escola. As teses sobre a desvalorização e desqualificação do trabalho docente que foram amplamente aceitas nas décadas passadas têm sido revistas à luz dessas mudanças. As discussões sobre a profissionalização e "desprofissionalização", bem como as pesquisas sobre identidade docente, tentam interpretar essas mudanças a partir de referências que levem em conta não só as relações de trabalho. Contudo, consideramos que um processo de desvalorização e precarização do trabalho docente tem se agravado nos últimos anos com as mudanças mais recentes introduzidas nas escolas latino-americanas. Essas mudanças trazem novos desafios para os trabalhadores docentes e para os que fazem desses seus objetos de investigação e análise.

\section{Referências Bibliográficas}

APPLE, M. W. Trabalho docente e textos: economia política das relações de classe e de gênero em educação. Porto Alegre: Artes Médicas, 1995.

ARROYO, M. Mestre, educador e trabalbador: organização do trabalho e profissionalização. Tese (Concurso de professor titular) - Faculdade de Educação da UFMG, Belo Horizonte, 1985.

BALL, S. J. Reformar escolas/reformar professores e os territórios da performatividade. Revista Portuguesa de Educação. Braga, Portugal, Universidade do Minho, n. 2, v. 15, 2002.

BARROSO, J. A escola pública: regulação, desregulação e privatização. Porto: Asa Editores, 2003.

BARROSO, J. Os novos modos de regulação das políticas educativas na Europa: da regulação do sistema a um sistema de regulações. Educação em Revista. Belo Horizonte, Faculdade de Educação/UFMG, n. 39, 2004.

BAUMAN, Z. Globalização: as conseqüências humanas. Rio de Janeiro: Zahar Editores, 1999.

BIRGIN, A. La docência como trabajo: la construcción de nuevas pautas de inclusión y exclusión. In: GENTILI, P.; FRIGOTTO, G. (Org.). La ciudadanía negada: políticas de exclusión en la educación y el trabajo. Buenos Aires: CLACSO, 2000. 
BRASIL. Parâmetros Curriculares Nacionais. Brasilia, 1995. (Documento Introdutório). BRASIL. Lei de Diretrizeses e Bases da Educasão Nacional. Lei n. 9.394 de 20 dez. 1996.

BRASIL. Lei n. 9424 de 24 deæ. 1996. Dispõe sobre o Fundo de Manutenção e Desenvolvimento do Ensino Fundamental e de Valorização do Magistério, na forma prevista no art. $60, \int 7^{\circ}$, do Ato das Disposições Constitucionais Transitórias, e dá outras providências.

BRASIL. Constituição da República Federativa do Brasil. 18. ed., atualizada e ampliada. São Paulo: Saraiva, 1998.

CALCAGNO, A. Ajuste estructural, costo social y modalidades de desarollo en América Latina. In: SADER, E. (Org.). El ajuste estructural en América Latina costos sociales y alternativas. Buenos Aires: CLACSO, 2001.

CARNOY, M. Razôes para investir em educação básica. Brasília: UNICEF/MEC, 1992.

CASTEL, R. As metamorfoses da questão social: uma crônica da questão social. Petrópolis: Vozes, 1999.

CATTONAR, B.; MAROY, C. Rhétorique du changement du métier d'enseignant et stratégie de transformation de l'institution scolaire. Revue Éducation et Sociétés, Paris/Bruxelles, Département De Boeck Université, n. 6/2000/2, 2001.

CEPAL. Transformación productiva con equidad. Santiago, 1990.

CEPAL/UNESCO. Educación y conocimiento: eje de la transformación productiva con equidad. Santiago, 1992.

CONTRERAS, J. Autonomia de professores. São Paulo: Cortez, 2002.

CNTE. Relatório de pesquisa sobre a situação dos trabalhadores (as) da educação básica. Retratos da Escola 3. Brasília, 2003.

DALE, R. Globalização e educação: demonstrando a existência de uma cultura educacional mundial comum ou localizando uma agenda globalmente estruturada para a educação. Educação, Sociedade e Culturas, Porto, Portugal, n. 16, p. 133-169, 2001.

DECLARAÇÃO mundial sobre educação para todos e plano de ação para satisfazer as necessidades básicas de aprendizagem. Nova York: UNICEF, 1990.

DELORS, J. Educação: um tesouro a descobrir. São Paulo/Brasília: Cortez; MEC/ UNESCO, 1998.

DUTERCQ, Y.; LANG, V. L'emergence d'un espace de régulation intermédiaire dans le système scolaire français. Revue Éducation et Sociétés, Paris/Bruxelles, Département De Boeck Université, n. 8/2001/2, 2002.

FANFANI, E. T. La condición docente. Buenos Aires: Siglo Veintiuno Editores, 2005. 
HARGREAVES, A. Os professores em tempos de mudança: o trabalbo e a cultura na idade pós-moderna. Alfragide: Editora McGraw-Hill, 1998.

KHERROUBI, M.; ZANTEN, A. V. La coordination du travail dans les établissements "difficiles": collégialité, division des roles et encadrement. Revue Éducation et Sociétés, Paris/Bruxelles, Département De Boeck Université, n. 6/ 2000/2, 2001.

LAS REFORMAS EDUCATIVAS en los países del cono sur: un balance crítico. Buenos Aires: CLACSO, 2005.

LESSARD, C.; TARDIF, M. Les transformations actuelles de l'enseignement: trois scénarios possibles dans l'évolution de la profession enseignante? In: LESSARD, C.; TARDIF, M. La profession d'enseignant aujourd'bui: évolutions, perspectives et enjeux internationaux. Montréal: La Presses de L’Université Laval, 2004.

LESSARD, C. L'obligation de resultats en éducation: de quoi s'agit-il? Le contexte québécois d'une demande sociale, une rhétorique du changement et une extension de la recherche. In: LESSARD, C.; MEIRIEU, P. L'obligation de resultats en éducation. Montréal: La Presses de L’Université Laval, 2004.

LEVASSEUR, L.; TARDIF, M. Les rapports professionnels entre les techniciens et les enseignants dans la division du travail au Québec. Revue Éducation et Sociétés, Paris/Bruxelles, Département De Boeck Université, n. 15/2005/1, 2005.

MEDINA, S. A.; KELLY, E. P. Professionnalisme et procés de formation: l'expérience latino-américaine. Revue Éducation et Sociétés, Paris/Bruxelles, Département De Boeck Université, n. 6/2000/2, 2001.

NORONHA, M. M. B. Condições do exercício profissional da professora e os seus possiveis efeitos sobre a saúde: estudo de casos das professoras do ensino fundamental em uma escola pública de Montes Claros, Minas Gerais. Dissertação (Mestrado) Programa de Pós-graduação em Saúde Pública, Mestrado Interinstitucional. Belo Horizonte, UFMG/UNIMONTES, 2001.

OLIVEIRA, D. A. Educaşão básica: gestão do trabalho e da pobreza. Petrópolis: Vozes, 2000.

Reforma educacional na América Latina e os trabalhadores docentes. Belo Horizonte: Autêntica, 2003.

A reestruturação do trabalho docente: precarização e flexibilização. Educ. Soc., v. 25, n. 89, p. 1.127-1.144, dez. 2004.

OLIVEIRA, D. A.; MELO, S. D. Estudio de los conflitos en los sistemas educativos de la región: agendas, actores, evolucion, manejo e desenlaces. Santiago: LPP/UERJ/ OREALC/UNESCO, 2004. (Relatório de estudo de caso do Brasil).

OLIVEIRA, D. A.; GONÇALVES, G. B. B. A gestão democrática da educação e o trabalho do diretor escolar (Apresentação de trabalho). $V$ Encontro da ANPED/Sudeste, Águas de Líndóia, 2002. 
ORGANIZAÇÃO DE ESTADOS IBERO-AMERICANOS PARA A EDUCAÇÃO, A CIÊNCIA E A CULTURA. Informe: governabilidade democrática e dos sistemas educacionais. Trad. Áurea Maria Corsi. Cadernos de Pesquisa, São Paulo, n. 100, 121-148, mar. 1997. (Número temático especial: Globalização e políticas Educacionais na América Latina).

POCHMANN, M. O trabalho sob fogo cruzado: exclusão, desemprego e precarização no final do século. São Paulo: Contexto, 1999.

POPKEWITZ, T. S. Reforma Educacional: uma política sociológica. Porto Alegre: Artes Médicas, 1997.

PREAL. Profesion docente. Disponível em: <http://www.preal.org>. Acesso em: 28 nov. 2006.

ROBITAILLE, M. L'identité professionnelle enseignante dans les Collèges d'enseignement général et professionnel: un chantier de trente ans. Revue Éducation et Sociétés. Paris/Bruxelles, Département De Boeck Université, n. 6/2000/2, 2001.

SADER, E. Quando novos personagens entraram em cena: experiências e lutas dos trabalhadores da grande São Paulo 1970-1980. Rio de Janeiro: Paz e Terra, 1981.

SALAMA, P.; VALIER, J. Pobrezas e desigualdades no Terceiro Mundo. São Paulo: Nobel, 1997.

Recebido em: 30/09/2006

Aprovado em: 06/11/2006 